\title{
Investigation of Wind Power Penetration Potential for Sri Lanka Power System
}

\author{
M.D.R. Nayomi and Lalith A. Samaliarachchi
}

\begin{abstract}
During the last few decades, the world has focused on harnessing renewable energy, owing to the increased fossil fuel consumption and the depletion rate of conventional energy reserves. When compared with other renewable energy sources, wind energy is relatively cheap due to its availability and free accessibility. In Sri Lanka, the island consists of abundant wind power potential in some clusters, though they are not being used in a prospective manner in electricity generation. The wind plants are lacking the characteristics of synchronous machines owing to wind intermittency, and less or even no inertia. As such, wind intermittency has become a governing factor in power system control and frequency stability. Therefore, it is necessary to find the maximum wind penetration level that can be absorbed by a power system, not only for smooth operation but also for future planning and issuance of licenses for the potential investors in this field. In this research paper, a novel method is presented to determine maximum wind penetration level using wind ramp to assure a reliable power supply. In here, modeling of the wind ramp representing its intermittency is the key factor. To determine the appropriate wind penetration level, frequency stability along with related transient stability studies are carried out to ascertain stable operation of the Sri Lanka power system. Prior to the determination of wind penetration levels, the system model of the central power system is validated to ensure the reliability of results. All the required power system simulations are carried out using the PSS®Esoftware assuming 5\% spinning reserve and 9 MW per minute wind ramp. The study revealed that the wind power penetration levels for Sri Lanka power system are $300 \mathrm{MW}$ and $540 \mathrm{MW}$ at base load level, $540 \mathrm{MW}$ and $660 \mathrm{MW}$ at night peakload level in 2021 and 2025, respectively.
\end{abstract}

Keywords: Wind power penetration, Wind ramp, Frequency stability, Transient stability

\section{Introduction}

Crucial drawbacks of generating electricity from fossil fuels are environmental hazards, finite energy sources, public health issues, overdependence, and rising cost etc. [1,2]. Therefore, many countries are focused on renewable energy sources and concerned about green energy concepts. When comparing with the other available renewable energy sources, such as solar, biomass, geothermal, wave and tidal etc., wind energy is relatively cheaper [3]. Also, wind is an infinite primary energy source available to mankind with minimal environmental impact. Therefore, many countries have now decided to lead their path towards robust growth of wind power generation.

The term wind penetration signifies the amount of power produced by wind plants compared to the total system generation [4]. The primary goal of increasing the wind penetration level in a power system is to reduce the primary fuel consumption and its associated costs while minimizing the environmental impact. Although Sri Lanka consists of abundant wind power potential in some areas, until 2019 , only about $128 \mathrm{MW}$ of wind power plants were connected to the national grid [5] and they are: Norochchole (60MW), Narakkalliya (21MW), Puttalam (22MW), Kilinochchi (21MW) and Nuwara Eliya $(4 \mathrm{MW})$. The variable nature of wind velocity called intermittency, fluctuates the power and energy produced by wind power plants. As such, the wind turbine/generators cannot be used in synchronism with the conventional synchronous machines. Therefore, wind power plants are unable to supply firm power continuously to the system and, as a result, the tolerable system frequency limit is difficult to be maintained. Moreover, the system frequency is highly affected by the inertia contribution by power plants and the very stochastic nature of wind, and it is less or sometimes no inertia at all makes the situation even worse. Under the circumstances, determination of wind power penetration level of a power system cannot

Miss. M.D.R. Nayomi, B.Tech. Eng. (Undergraduate),

The Open University of Sri Lanka

ORCID ID: https://orcid.org/0000-0001-7841-6995

Eng. Lalith A. Samaliarachchi, C. Eng., MIE(SL), MIEE(UK), B.Sc. Eng. (Hons) (Moratuwa), M. Eng. (AIT),Senior Lecturer, Department of Electrical \& Computer Engineering, The Open University of Sri Lanka

ORCID ID: https://orcid.org/0000-0001-9447-4757 
be decided without doing a detailed analysis and is an essential figure in power system planning operation and control. In this paper, a novel method, i.e., wind ramp to represent wind intermittency, is proposed to determine the wind absorption level.

The wind ramp, which cannot be disregarded is an input parameter, characterises the wind intermittency, and modelling the same to determine the penetration level has become a crucial factor. In here, the wind ramp is modelled using python programming language prior to all the system simulation studies. Simulations were conducted using PSS $® E$ Esoftware and the results are evaluated with respect to the Sri Lanka power system.

The study demonstrates the effective areas for wind integration and the maximum wind penetration potential for years 2021 and 2025 . Further, the outcome of this study helps the wind plant developers to obtain more ideas based on the wind power potential and the specific clusters for wind integration. It also provides help to utilities for their future generation and transmission planning purposes, as well as help the government to grant permission for future development projects.

\section{Literature Review}

Several researches have attempted to determine the maximum level of wind penetration level into power systems. In order to estimate the maximum wind power penetration level, transient frequency deviation index and centre of inertia (COI) techniques are used [6]. The results of the procedures are established through the dynamic simulation of WSCC 9bus system. In [7], the maximum wind penetration level is evaluated based on the available spinning reserve (SR) capacity of diesel engines and gradual increase without affecting the system stability. Minimum frequency level and the rate of change of frequency (ROCOF), following an outage of the largest generator of a power system, are considered to evaluate the maximum wind penetration level with 250-bus system in [8]. Transient and frequency stability criteria are being considered to determine the wind penetration level [9] and the proposed method is evaluated using IEEE9-bus system. In [10], box set robust optimization theory is used to determine the maximum wind capacity penetration.

\section{Wind Resource Potential}

There are several prospective wind potential areas identified in Sri Lanka for the effective wind power generation by Sustainable Energy Authority of Sri Lanka. It has been acknowledged and established that a large amount of wind power potential is gained through monsoons. There are two main types of monsoons and two types of inter monsoons that contribute to these phenomena [11], and can be categorized as: north-east monsoon (NEM)(Dec.-Feb.), south-west monsoon (SWM) (May-Sep.), first inter-monsoon (Mar.-Apr.) and second inter-monsoon (Oct.-Nov.), respectively. During the said monsoons, there are about five clusters in Sri Lanka that shows a better wind potential. These clusters provide a basic idea for developing wind parks and their adequate capacities of wind potential [12]. Table 1 depicts the areas identified for wind integration with their maximum potentials.

Table 1 - Potential Areas for Wind Integration

\begin{tabular}{|c|l|c|}
\hline No. & \multicolumn{1}{|c|}{ District } & $\begin{array}{c}\text { Wind resource } \\
\text { potential (MW) }\end{array}$ \\
\hline 1 & Hambantota $(\mathrm{H})$ & 137 \\
\hline 2 & Jaffna $(\mathrm{J})$ & 380 \\
\hline 3 & Puttalam (P) & 123 \\
\hline 4 & Kilinochchi (K) & 240 \\
\hline 5 & Mannar (M) & 350 \\
\hline
\end{tabular}

\section{Suitable Time Period for Wind Integration}

Although wind power can be harnessed from the four monsoons, an adequate wind speed range should be identified to acquire the maximum power and energy production from wind plants. Therefore, an appropriate time period for wind integration has to be established. Since the generation dispatch of Sri Lanka power system is not the same throughout the year and varies based on the period of operation concerned, the wind integration time period plays a very significant role in preparing the generator dispatch schedule.

As per the global wind atlas (GWA) [13], the average wind speed obtained throughout the year is shown in Table 2. It can be observed that the rated wind speed $(>9 \mathrm{~m} / \mathrm{s})$ occurs in May to September period and hence the maximum wind power and energy can be harnessed during this period. Wind speeds of the other months are below or approximately equal to 
the cut-in speed $(3 \mathrm{~m} / \mathrm{s}-5 \mathrm{~m} / \mathrm{s})$, hence the rated power cannot be harnessed during October to April. In addition, as can be seen from wind speed indexes (attached in Appendix A, Figures A1-A5) along with the appropriate wind roses (attached in Appendix B, Figures B1-B5) for the five clusters, the most suitable time period for harnessing wind power can be identified as from May to September (SouthWest monsoon).

Table 2 - Average Wind Speed(m/s) at Five Clusters

\begin{tabular}{|c|c|c|c|c|c|}
\hline District & $\mathrm{M}$ & $\mathrm{P}$ & $\underset{\mathrm{J}}{\mathrm{P}}$ & $\begin{array}{c}\mathrm{K} \\
\text { Mannar }\end{array}$ & $\begin{array}{c}\mathrm{H} \\
\text { Puttalam }\end{array}$ \\
\hline Janffna & Kilinochchi & Hambantota \\
\hline February & 5.4 & 6.7 & 7.0 & 6.5 & 7.4 \\
\hline March & 4.7 & 6.0 & 5.4 & 5.0 & 6.7 \\
\hline April & 4.7 & 5.0 & 4.6 & 4.3 & 4.7 \\
\hline May & 9.0 & 9.2 & 10.5 & 9.7 & 8.0 \\
\hline June & 10.5 & 10.6 & 10.9 & 10.3 & 8.4 \\
\hline July & 9.0 & 10.0 & 9.4 & 9.0 & 8.4 \\
\hline August & 9.0 & 9.6 & 9.3 & 9.0 & 8.3 \\
\hline September & 9.0 & 9.2 & 9.4 & 8.7 & 7.9 \\
\hline October & 5.5 & 6.0 & 6.2 & 5.8 & 5.5 \\
\hline November & 4.1 & 5.0 & 6.2 & 5.7 & 4.0 \\
\hline December & 5.4 & 6.1 & 7.3 & 7.2 & 6.4 \\
\hline
\end{tabular}

The generation dispatch and the maintenance schedule of the generators considered during power system simulation studies in this research work are obtained from the system control center (SCC) of Ceylon Electricity Board.

\section{Model Validation}

In most of the power system evaluations, validation is an essential part assuring the reliability of results and helpful to ensure an accurate modelling of the system. Comparison of the recorded sequence of events after a major disturbance of a power system with a computer simulated result is a well-known exercise in model validation in most of the utilities worldwide. Even though perfect matching between the real and simulated results are not needed, it is necessary to match the results to an acceptable level with the plant's dynamic behaviour. The model validation methodology carried out in this study is illustrated in Figure 1 as described below.

Step-1: Create the power system model structure to be used for modelling the actual outage.
Step-2: Collect the recorded data, with respect to an actual disturbance from digital fault recorder (DFR).

Step-3: Simulate the actual outage in the modelled structure.

Step-4: Compare the simulated results obtained from Step 3 with the recorded data gathered from Step 2.

If the simulated result matches with the actual recorded data adequately, validation of the model is accepted.

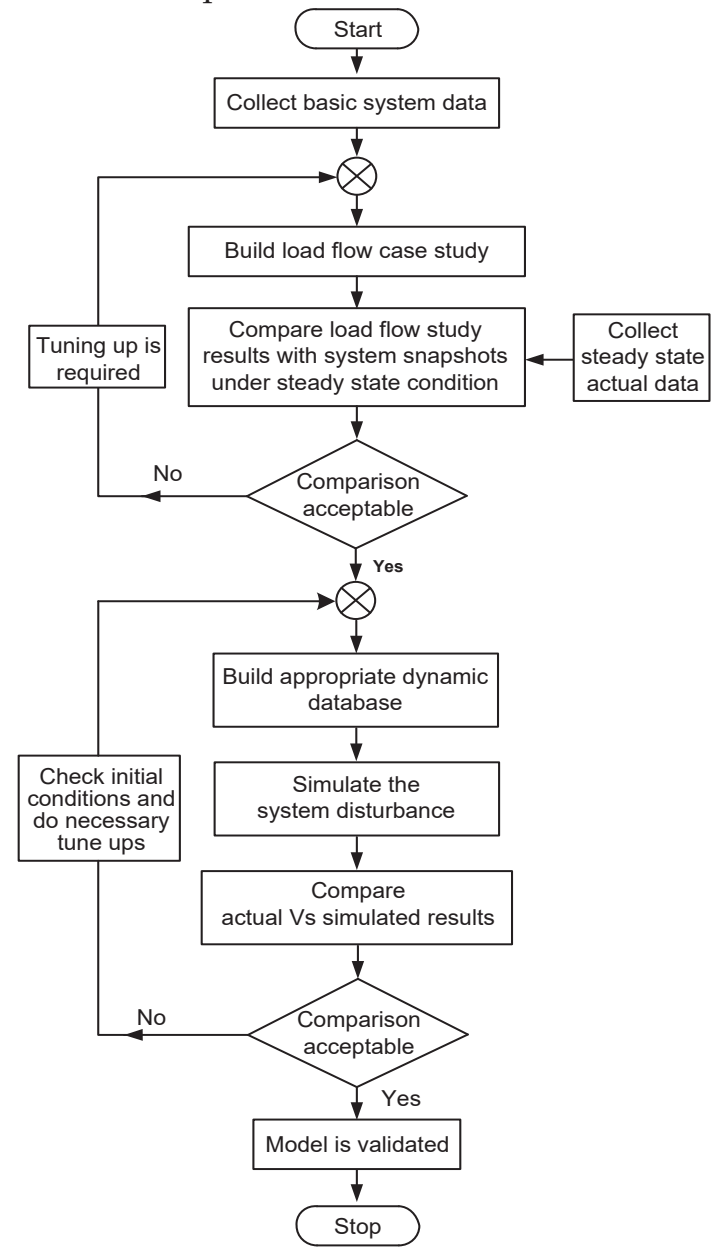

Figure 1 - Flow Chart showing the Methodology for Model Validation

\section{Programming of Python Code}

The wind power penetration level is highly variable owing to its intermittency [14]. As such, modelling of ramping to represent intermittency is an essential part in this research study. Wind ramp code, an additional input required to execute PSS®Esoftware, was written using Python programming language. The ramp rate defined for grid substation shall not exceed $10 \mathrm{MW} /$ minute [15]. Assumed ramp rate in this study is $9 \mathrm{MW} /$ minute. Table 3 depicts the wind ramp data considered for a 60 MW wind plant followed by Figure 2 that illustrates the variation of system frequency 
with wind ramp during randomly picked up system load flow snapshot.

\section{Table 3 - Wind Ramp for 60 MW Wind Plant}

\begin{tabular}{|c|c|}
\hline $\begin{array}{c}\text { Time } \\
(\mathrm{s})\end{array}$ & $\begin{array}{c}\text { Power } \\
(\mathrm{MW})\end{array}$ \\
\hline 0 & 60.0 \\
\hline 5 & 59.25 \\
\hline 10 & 58.5 \\
\hline 15 & 57.75 \\
\hline 20 & 57.0 \\
\hline 25 & 56.25 \\
\hline 30 & 55.5 \\
\hline
\end{tabular}

\begin{tabular}{|c|c|}
\hline $\begin{array}{c}\text { Time } \\
(\mathrm{s})\end{array}$ & $\begin{array}{c}\text { Power } \\
(\mathrm{MW})\end{array}$ \\
\hline 35 & 54.75 \\
\hline 40 & 54.0 \\
\hline 45 & 53.25 \\
\hline 50 & 52.5 \\
\hline 55 & 51.75 \\
\hline 60 & 51.0 \\
\hline
\end{tabular}

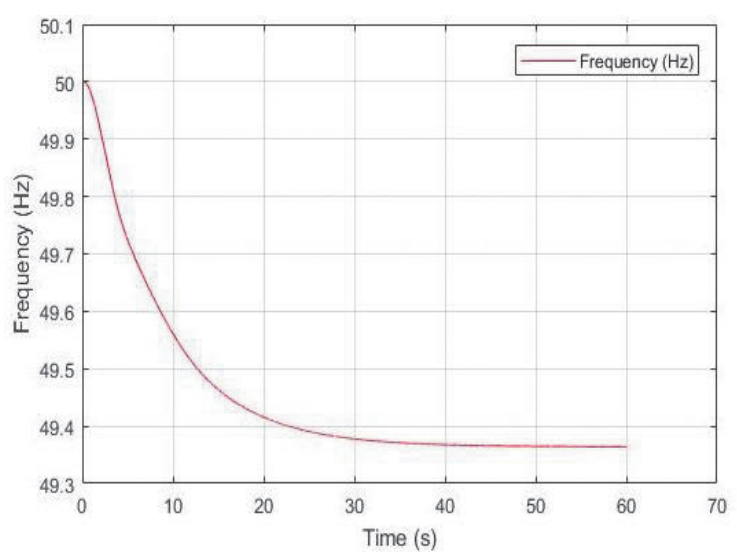

Figure 2 - System Frequency Variation with Wind Ramp

\section{Proposed Methodology}

In this research study, a novel method to determine the wind penetration level for the Sri Lanka power system is introduced. All the principles stated here are compatible with the grid code standards of Sri Lanka power system. There are three main steps involved in this process and they are:

\section{Step-1: Steady state load flow analysis}

This is the most important, basic and essential part of the process. It provides the information related to the prevailing power system such as voltages at nodes, overloaded elements, weak points of the network, line losses, slack bus summary, etc. Once the simulated system is fine-tuned and considered acceptable with steady state load flow analysis, the process can be moved towards Step 2. If not, remedial measures should be taken until the results are within acceptable limits.

Step-2: Frequency Stability Analysis (FSA)

In here, the frequency behavior of the system is investigated with a wind ramp over a 60 s period and is applied for every 60MW step addition at a rate of $9 \mathrm{MW} /$ minute. The anticipated system frequency variation should be within the range of $\pm 1 \%(49.5 \leq f \leq 50.5) \mathrm{Hz}$. The system frequency decreases when more and more wind plants are added to the system owing to wind ramp. Wind plant capacity addition is repeated until such time the frequency drops and reaches the allowable minimum system frequency level of $49.5 \mathrm{~Hz}$. If not, the process should be moved to Step 3 .

\section{Step-3: Transient Stability Analysis (TSA)}

TSA evaluates the power system stability after a severe system disturbance. In here, the system is tested again with 60 s wind ramp with the disturbance applied immediately after the $60 \mathrm{~s}$ period. Since the worst-case disturbance that can be identified in prevailing Sri Lanka power system is a single unit tripat Norochchole coal power plant, the forced outage of a 300MW unit is simulated for TSA.

If the system is found to be stable, the cumulative additions of wind power is selected to be the wind penetration level and, if not, necessary measures should be taken to finetune the cases and rectify the problems occurred during TSA. The flow chart of the proposed methodology is shown in Figure 3.

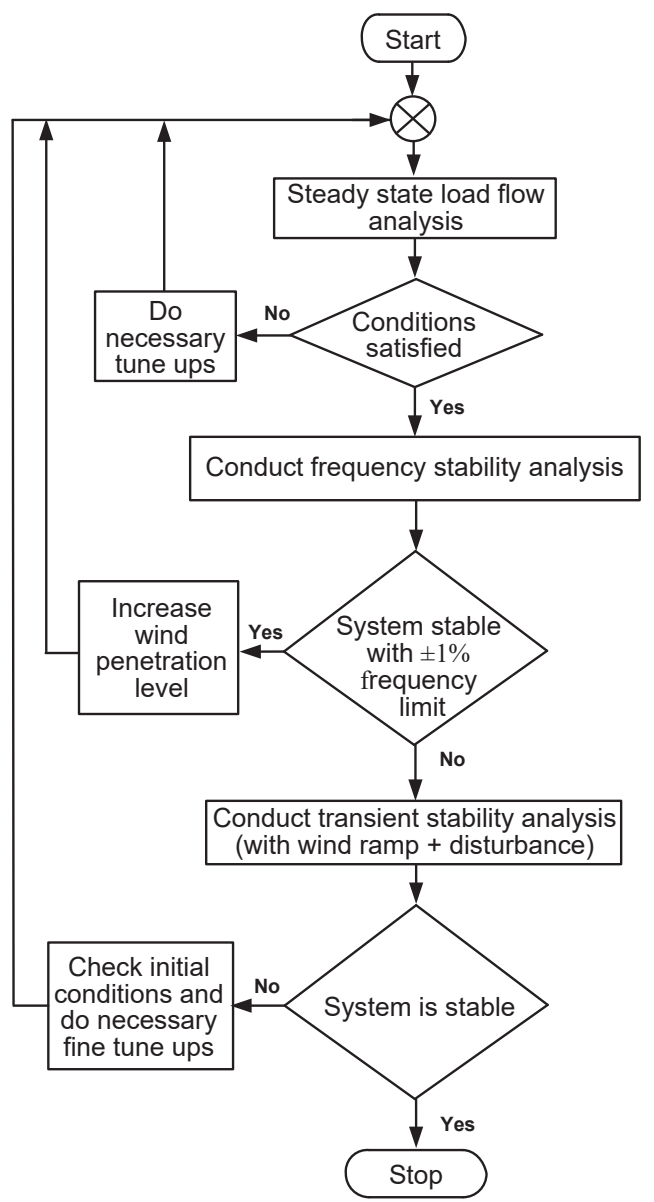

Figure 3 - Flow Chart Showing the Proposed Methodology 


\section{Results and Discussion}

\subsection{Model Validation}

The model validation is carried out with the real time disturbance that occurred at No rochchole coal power plant, i.e., unit - 1 tripped on 7 November 2017. Actual data corresponding to the said disturbance was obtained from the DFR readings. The comparison between the system frequency variation during real outage (blue) and the computer simulated frequency variation (red) is illustrated in Figure 4.

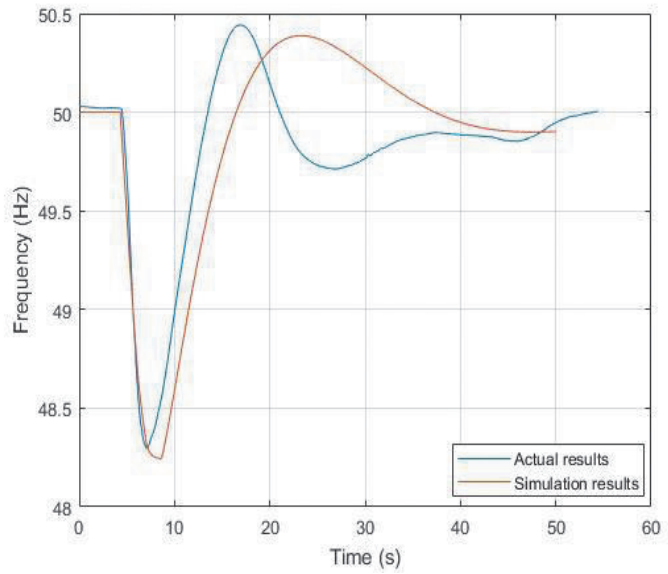

Figure 4 - Comparison between Actual and Simulated Results

As can be seen, a minor discrepancy can be observed between the actual and simulated results. This may be owing to some of the inherent missing data inputs. For near perfect one to one matching, all the actual real time data inputs related to the disturbance have to be collected and simulated.

\subsection{Wind Penetration Level for 2021}

\subsubsection{Frequency Stability Analysis-2021}

The impact of wind intermittency on system frequency in year 2021 is discussed in this section.

The constraints applied for the simulated study are:

$>$ Frequency fluctuations should be within $\pm 1 \%$ frequency limit

$>$ Wind ramp rate is $9 \mathrm{MW} / \mathrm{min}$

> System spinning reserve should be maintained at approximately $5 \%$.
The impact on system frequency is expected to be severe at lower load conditions owing to less system inertia. Therefore, initially the frequency stability analysis is carried out for the base load level. Thereafter, the impact owing to the higher load condition is investigated, i.e., during night peak load. This is done by sequentially adding 60MW wind plants to the system while simultaneously simulating the wind ramp and observing the minimum frequency step value. When the minimum system frequency hits the lower value of $49.5 \mathrm{~Hz}$, the wind plant addition is stopped. Figure 5 and Figure 6 illustrate the variation of system frequency under frequency stability analysis at base load level and night peak loads, respectively, and Table 4 summarizes the results of frequency stability analysis for the year 2021.

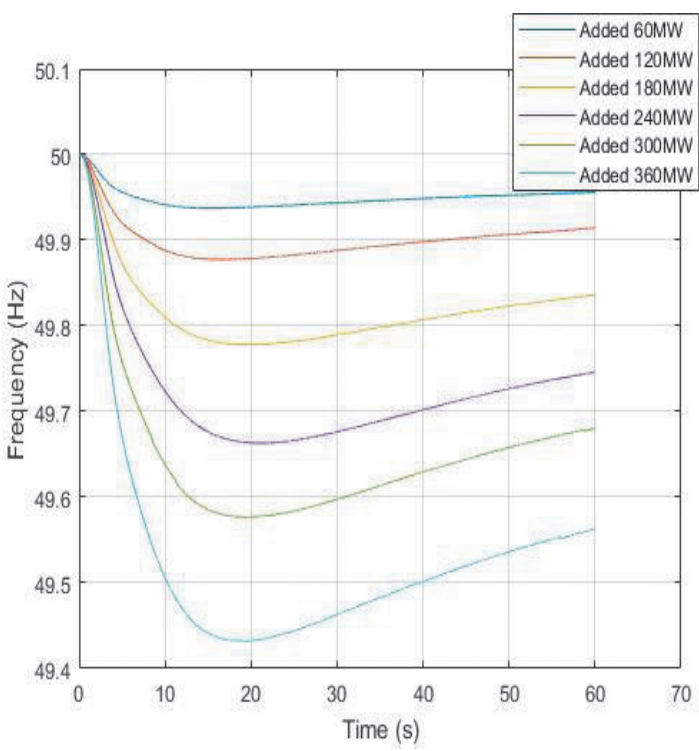

Figure 5 - Frequency Stability Results at Base Load-2021

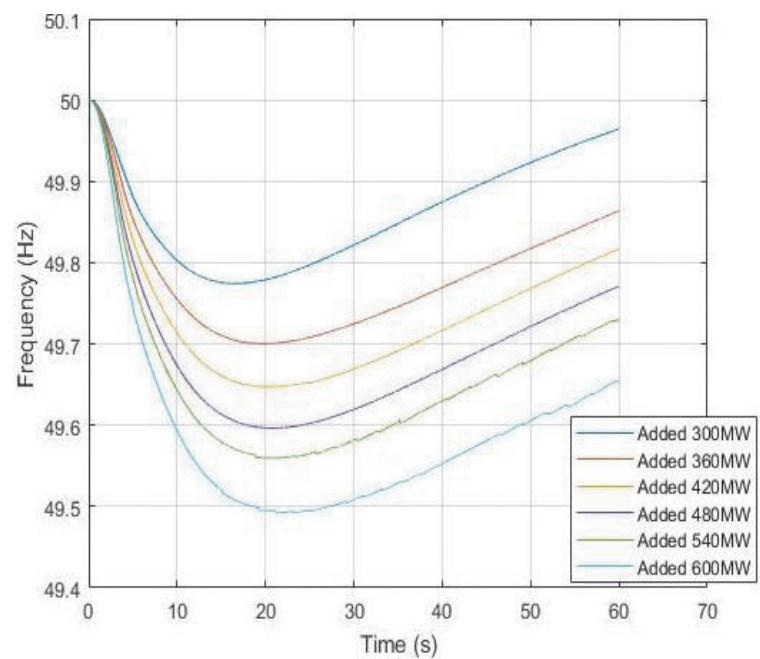

Figure 6 - Frequency Stability Results at Night Peak Load-2021 
Table 4 - Results of the Frequency Stability Analysis-2021

\begin{tabular}{|c|c|c|}
\hline $\begin{array}{c}\text { Added wind } \\
\text { power } \\
\text { capacity(MW) }\end{array}$ & $\begin{array}{c}\text { System frequency } \\
\text { variation with wind } \\
\text { ramp at base load }\end{array}$ & $\begin{array}{c}\text { System frequency } \\
\text { variation with wind } \\
\text { ramp at night peak }\end{array}$ \\
\hline 60 & $< \pm 1 \%$ & $< \pm 1 \%$ \\
\hline 120 & $< \pm 1 \%$ & $< \pm 1 \%$ \\
\hline 180 & $< \pm 1 \%$ & $< \pm 1 \%$ \\
\hline 240 & $< \pm 1 \%$ & $< \pm 1 \%$ \\
\hline 300 & $< \pm 1 \%$ & $< \pm 1 \%$ \\
\hline 360 & $> \pm 1 \%$ & $< \pm 1 \%$ \\
\hline 420 & $> \pm 1 \%$ & $< \pm 1 \%$ \\
\hline 480 & $> \pm 1 \%$ & $< \pm 1 \%$ \\
\hline 540 & $> \pm 1 \%$ & $< \pm 1 \%$ \\
\hline 600 & $> \pm 1 \%$ & $> \pm 1 \%$ \\
\hline
\end{tabular}

As can be depicted from the table, the permissible wind penetration level at base load level is 300MW and at the system night peak load level is 540MW in year 2021.

\subsubsection{Transient stability analysis - 2021}

Subsequent to the FSA, the transient stability analysis is conducted to confirm the stable operation of the power system. Single unit tripping at Norochchole coal power plant $(300 \mathrm{MW})$ is considered here.

While the wind ramp is effective and at the tail end of it (i.e. at 60s), the transient frequency stability of the power system is observed by applying the aforesaid disturbance. The results obtained at base load and night peak load transient stability simulations are shown in Figure 7 and Figure 8, respectively.

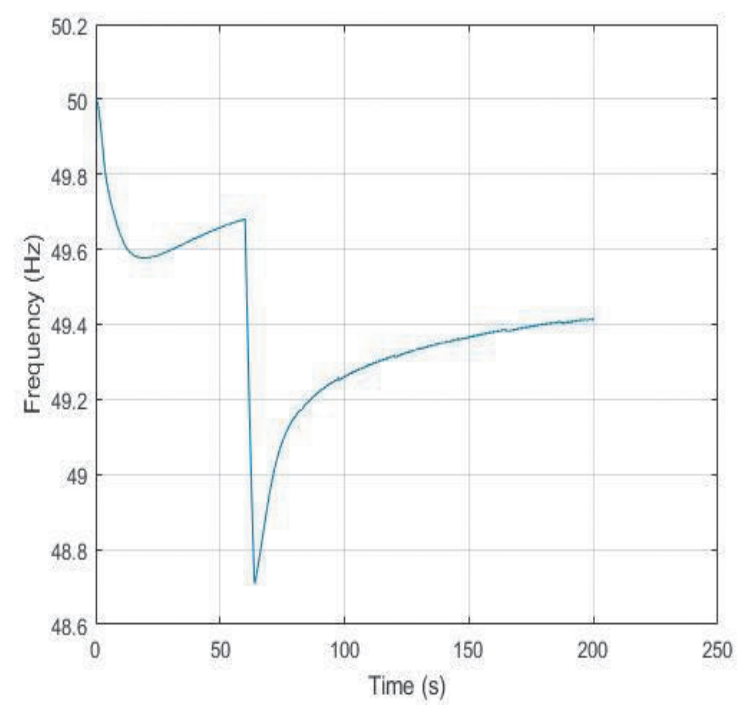

Figure 7 - Transient Stability Result at Base Load - 2021

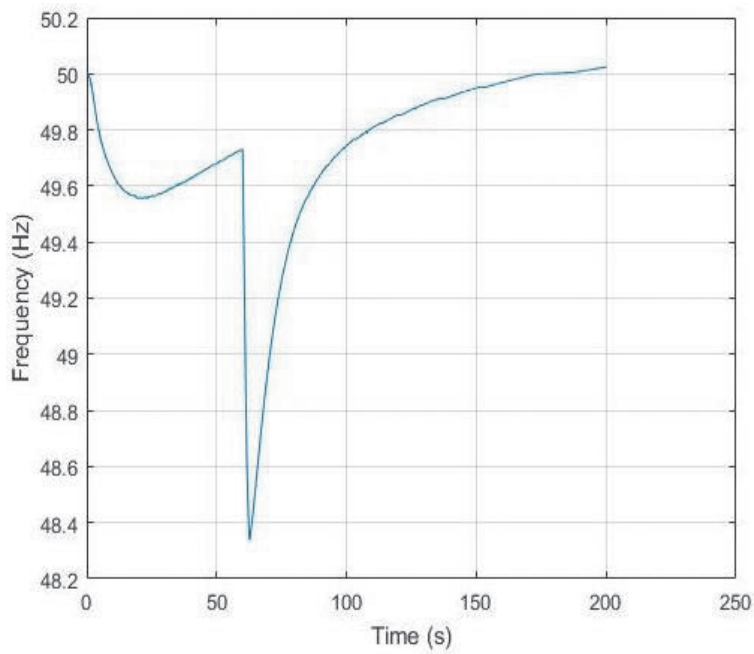

Figure 8 - Transient Stability Result at Night Peak Load - 2021

It is clear from both FSA and TSA studies that the system is stable for both baseload and night peak load scenarios in 2021. Therefore, it can be concluded that the system wind penetration level is 300MW at baseload level and 540MW at night peak load in 2021. Curtailment wind rate is $240 \mathrm{MW}$ at baseload.

\subsection{Wind penetration level for 2025}

\subsubsection{Frequency Stability Analysis - 2025}

Similarly, with the constraints considered in section 8.2.1, the impact of wind intermittency on the system frequency in 2025 is described in this section. Figures 9 and 10 illustrate the variation of system frequency under frequency stability analysis at base load and night peak load, respectively. Table 5 summarizes the observed results.

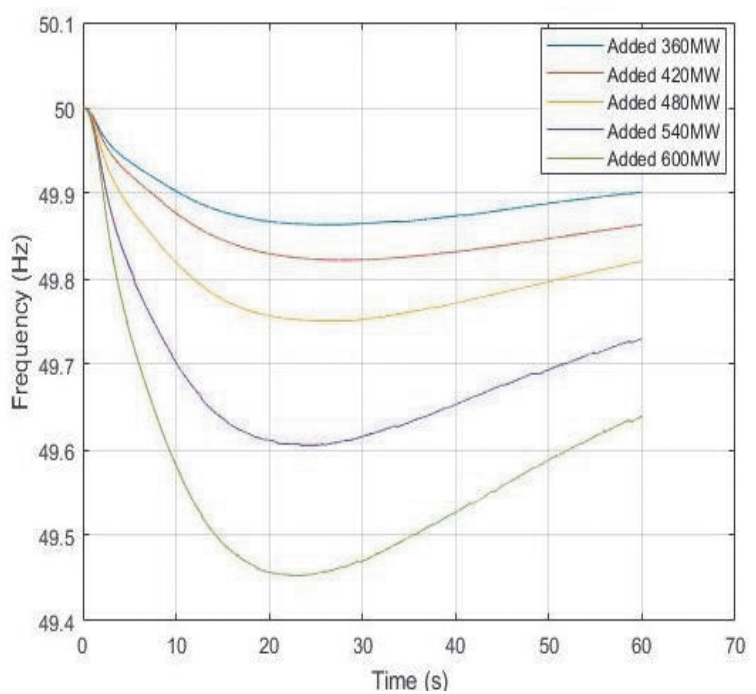

Figure 9 - Frequency Stability Results at Base Load - 2025 


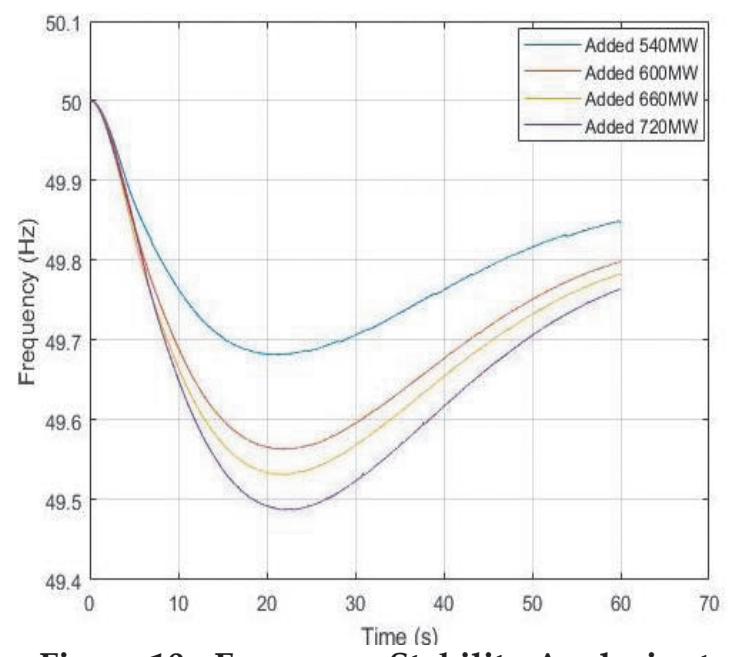

Figure 10 - Frequency Stability Analysis at Night Peak - 2025

Table 5 - Results obtained from the Frequency Stability Analysis - 2025

\begin{tabular}{|c|c|c|}
\hline $\begin{array}{c}\text { Added wind } \\
\text { power capacity } \\
\text { (MW) }\end{array}$ & $\begin{array}{c}\text { System frequency } \\
\text { variation with wind } \\
\text { ramp at baseload }\end{array}$ & $\begin{array}{c}\text { System frequency } \\
\text { variation with wind } \\
\text { ramp at night peak }\end{array}$ \\
\hline 360 & $< \pm 1 \%$ & $< \pm 1 \%$ \\
\hline 420 & $< \pm 1 \%$ & $< \pm 1 \%$ \\
\hline 480 & $< \pm 1 \%$ & $< \pm 1 \%$ \\
\hline 540 & $< \pm 1 \%$ & $< \pm 1 \%$ \\
\hline 600 & $> \pm 1 \%$ & $< \pm 1 \%$ \\
\hline 660 & $> \pm 1 \%$ & $< \pm 1 \%$ \\
\hline 720 & $> \pm 1 \%$ & $> \pm 1 \%$ \\
\hline
\end{tabular}

As can be seen from the table, permissible wind penetration level at base load is $540 \mathrm{MW}$ and at the night peak load is 660MW in year 2025.

\subsubsection{Transient stability analysis-2025}

Here too, the TSA studies are conducted to confirm the stable operation of the system configuration proposed in 2025. The results obtained from the base load and night peak load transient stability simulations are shown in Figure 11 and Figure 12, respectively. It is observed that the system is stable for both base load and night peak load conditions.

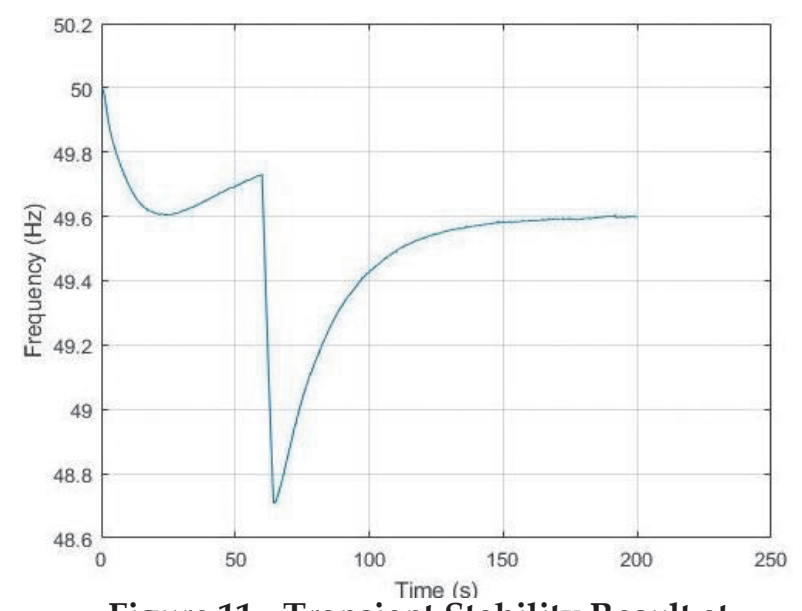

Figure 11 - Transient Stability Result at Base load

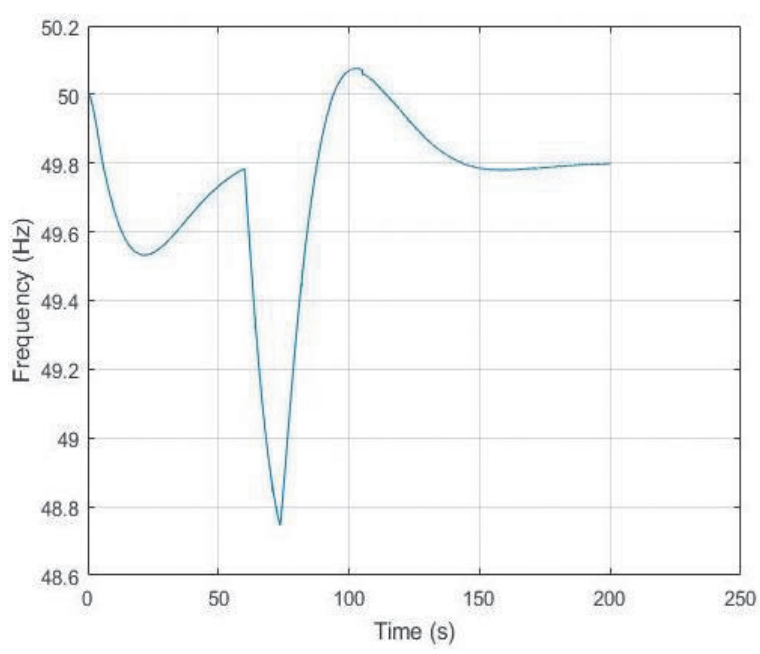

Figure 12 - Transient Stability Result at Night Peak - 2025

Table 6 depicts the results of wind penetration level study for years 2021 and 2025.

Table 6 - Wind Penetration levels for 2021 and 2025

\begin{tabular}{|c|c|c|c|c|}
\hline Year & $\begin{array}{c}\text { System } \\
\text { Baseload } \\
\text { (MW) }\end{array}$ & $\begin{array}{c}\text { Penetration } \\
\text { level } \\
\text { (MW) }\end{array}$ & $\begin{array}{c}\text { Night } \\
\text { peak load } \\
\text { (MW) }\end{array}$ & $\begin{array}{c}\text { Penetration } \\
\text { level } \\
\text { (MW) }\end{array}$ \\
\hline 2021 & 1615 & 300 & 3186 & 540 \\
\hline 2025 & 1977 & 540 & 3821 & 660 \\
\hline
\end{tabular}

\subsubsection{Discussion}

It is worthwhile at the end of the study to observe the areas which have been used to generate wind power for integration. Table 7 shows the details of the wind potential are as already integrated into the prevailing power system and the proposed wind farms identified to be integrated into the system in the near future (2021 and 2025 years). Table 8 shows the potential areas for wind integration and their capacities beyond 2025 .

Table 7 - Identified Wind Areas/Potentials

\begin{tabular}{|c|c|c|c|c|}
\hline $\begin{array}{c}\text { Yea } \\
\text { Up to } 2019\end{array}$ & $\begin{array}{c}\mathrm{P} \\
(\mathrm{MW})\end{array}$ & $\begin{array}{c}\mathrm{K} \\
(\mathrm{MW})\end{array}$ & $\begin{array}{c}\mathrm{M} \\
(\mathrm{MW})\end{array}$ & $\begin{array}{c}\mathrm{J} \\
(\mathrm{MW})\end{array}$ \\
\hline 2021 & 103 & 21 & & \\
\hline 2025 & & & 360 & 240 \\
\hline
\end{tabular}

Table 8 - Potential Areas and Capacities for Future Wind Integration Beyond 2025

\begin{tabular}{|c|c|}
\hline District & Wind Amount(MW) \\
\hline $\mathrm{K}$ & 219 \\
\hline $\mathrm{H}$ & 137 \\
\hline $\mathrm{P}$ & 20 \\
\hline $\mathrm{J}$ & 20 \\
\hline $\mathrm{M}$ & 0 \\
\hline
\end{tabular}




\section{Conclusion and Future Work}

In this research study, a novel method is proposed to determine the wind penetration level for the Sri Lankan power system proposed for the years 2021 and 2025. Initially, the prevailing power system network is modelled, simulated and validated with load flow studies and related stability studies to ensure the consistency and reliability of the output results. Since the wind power constantly fluctuates, modelling of the same to represent its intermittency is required, hence a wind ramp input is introduced to ascertain the system stability. Finally, the wind penetration level that can be permitted for the safe operation of Sri Lanka power system is established for the years 2021 and 2025.

While carrying out this research study, it was found that the wind absorption level is highly contingent upon the real time system inertia and hence the system spinning capacity. Higher the spinning capacity, higher the wind absorption level and vice versa with associated costs. Therefore, it is highly recommended for both Public Utility Commission of Sri Lanka and CEB to carryout system stability studies annually at identified critical benchmark load levels to establish appropriate wind penetration levels that can be absorbed by the power system, not only for smooth operation but also for future planning and issuance of licenses for the potential investors in this field.

\section{Acknowledgement}

The authors would like to offer their appreciation to Eng. Dr H. M. Wijekoon Banda, Chief Engineer, Transmission Planning Branch (CEB), for granting permission and providing relevant data for this study.

\section{References}

1. https://www.conserve-energyfuture.com/disadvantages_fossilfuels.php, Visited, 11 th May 2020.

2. https://energyinformative.org/fossil-fuelspros-and-cons/, Visited, 11 th May 2020.

3. https://www.powertechnology.com/features/cheapest-renewableenergy-sources/, Visited, 11 th May 2020.

4. https://en.wikipedia.org/wiki/Wind_power,Vi sited, 12th May 2020.
5. Transmission and Generation Planning Branch of CEB, Long Term Generation Expansion Plan 2020-2039 (Draft), 2020.

6. Athraalessa, Noor Izzri Abdul Wahab, Norman Mariun, Hashim Hizam, “Method of Estimating the Maximum Penetration Level of Wind Power Using Transient Frequency Deviation Index Based on COI Frequency", IEEE, June, 2017.

7. Chia-An Chang, Yuan-Kang Wu, Bin-Kwie Chen, Zhao-Guo Peng, "Determination of Maximum Wind Power Penetration in an Isolated Island System by Considering Spinning Reserve", IEEE, June, 2014.

8. Nahid-Al-Masood, Ruifeng Yan, Tapan Kumar Saha, "Estimation of Maximum Wind Power Penetration Level to Maintain an Adequate Frequency Response in a Power System", IEEE, January, 2015.

9. Ahmadi, H. and Ghasemi, H. "Maximum Penetration Level of Wind Generation Considering Power System Security Limits," IET, Vol. 6, November 2012, pp. 1164 - 1170.

10. LihuiGuo, Hao Bai, "Method for Determining the Maximum Allowable Capacity of Wind Farm Based on Box Set Robust Optimization", Hindawi Publishing Corporation, Volume 2015, November 2015.

11. http://www.meteo.gov.lk/index.php?option $=\mathrm{CO}$ m_content\&view $=$ article\&id $=94 \&$ Itemid $=310 \& l a$ ng=en\#2, Visited, 20 ${ }^{\text {th }}$ May 2020.

12. SLSEA, Renewable Energy Resource Inventory \& Resource Maps 2019, 2019.

13. https://globalwindatlas.info/, Visited, $2^{\text {th }}$ May 2020.

14. Ahmed G. Abo-Khalil, "Impacts of Wind Farms on Power System Stability", IEEEMarch, 2013, 2 $\mathrm{p}$

15. https://www.ceb.lk/front_img/tender_pdf/20 0305160341Addendum_to_grid_inter_guide_(W ind).pdf. 


\section{Appendix A - Wind Speed Indexes at 5 Clusters}

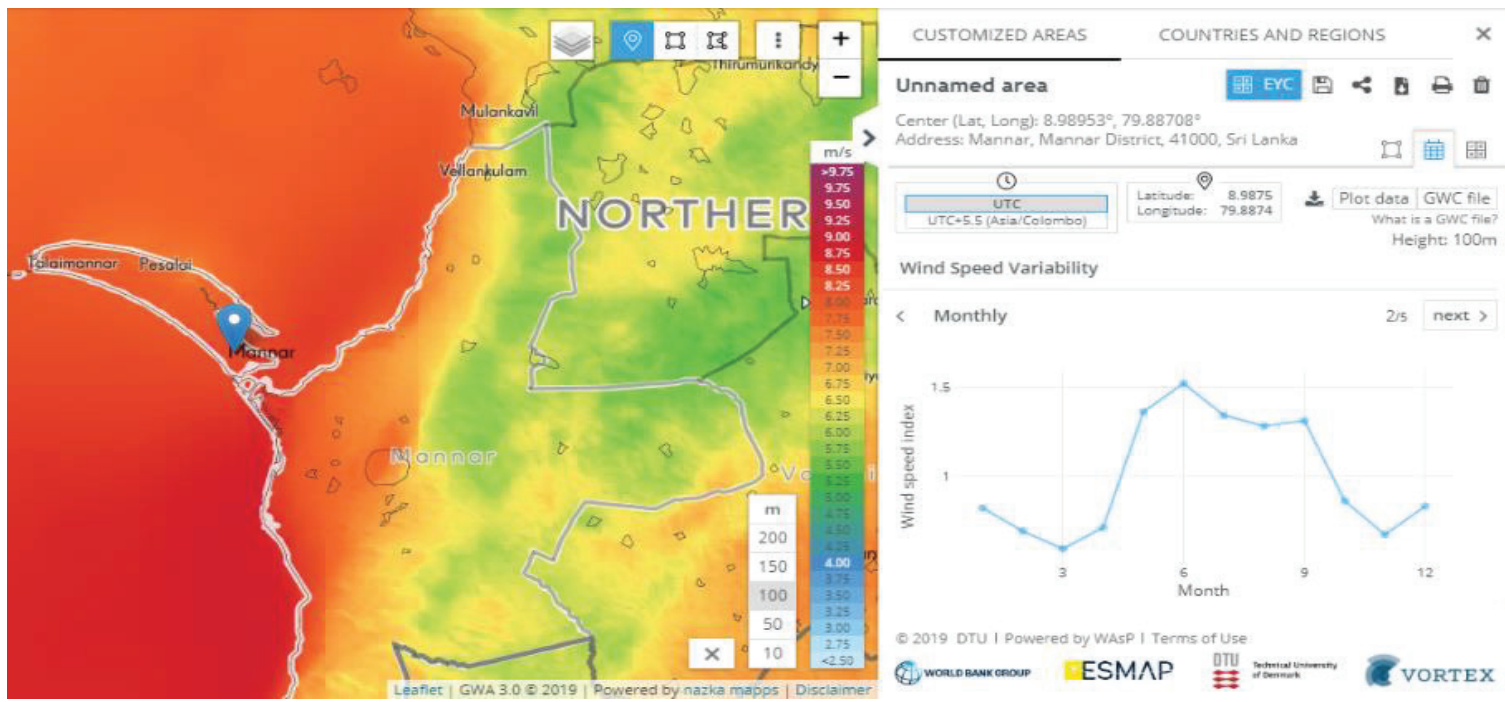

Figure A1 - Wind Speed Index at Mannar

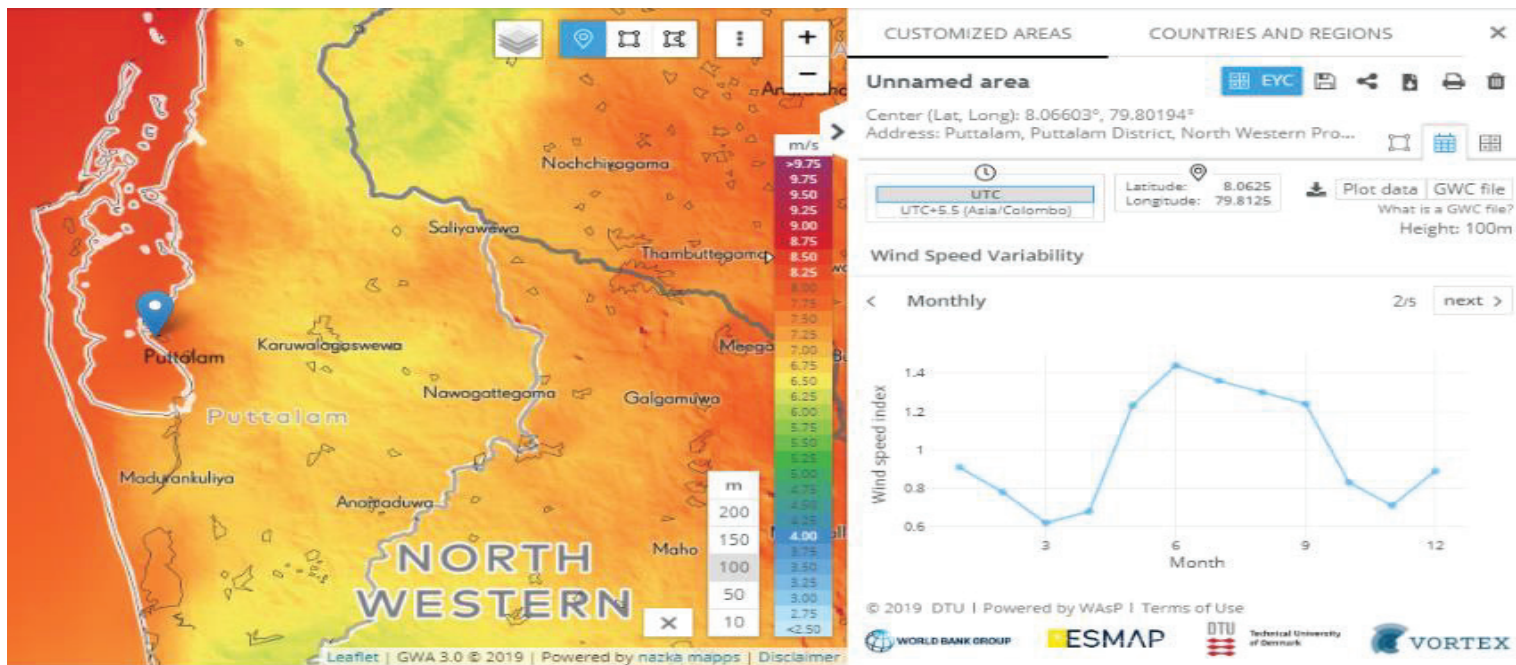

Figure A2 - Wind Speed Index at Puttalam

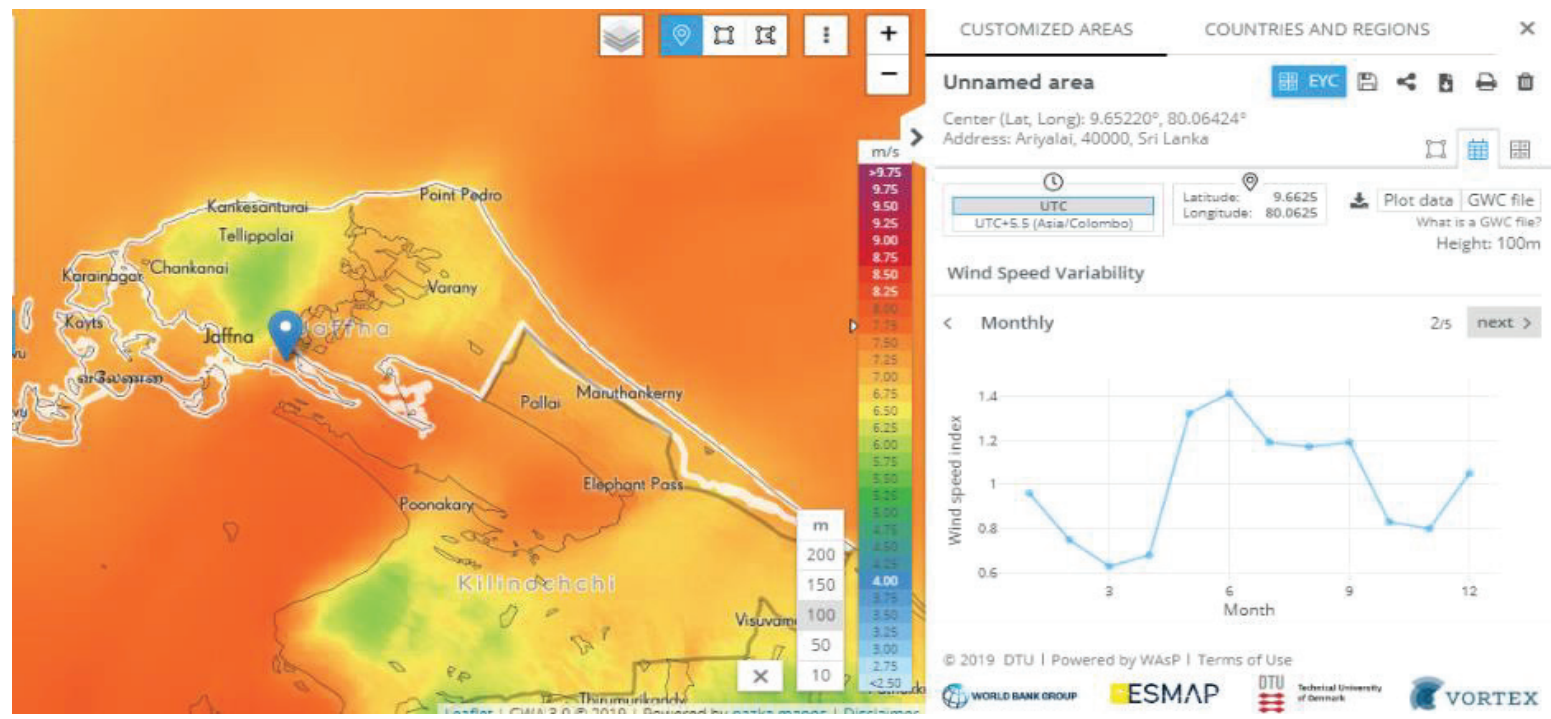


Figure A3 - Wind Speed Index at Jaffna

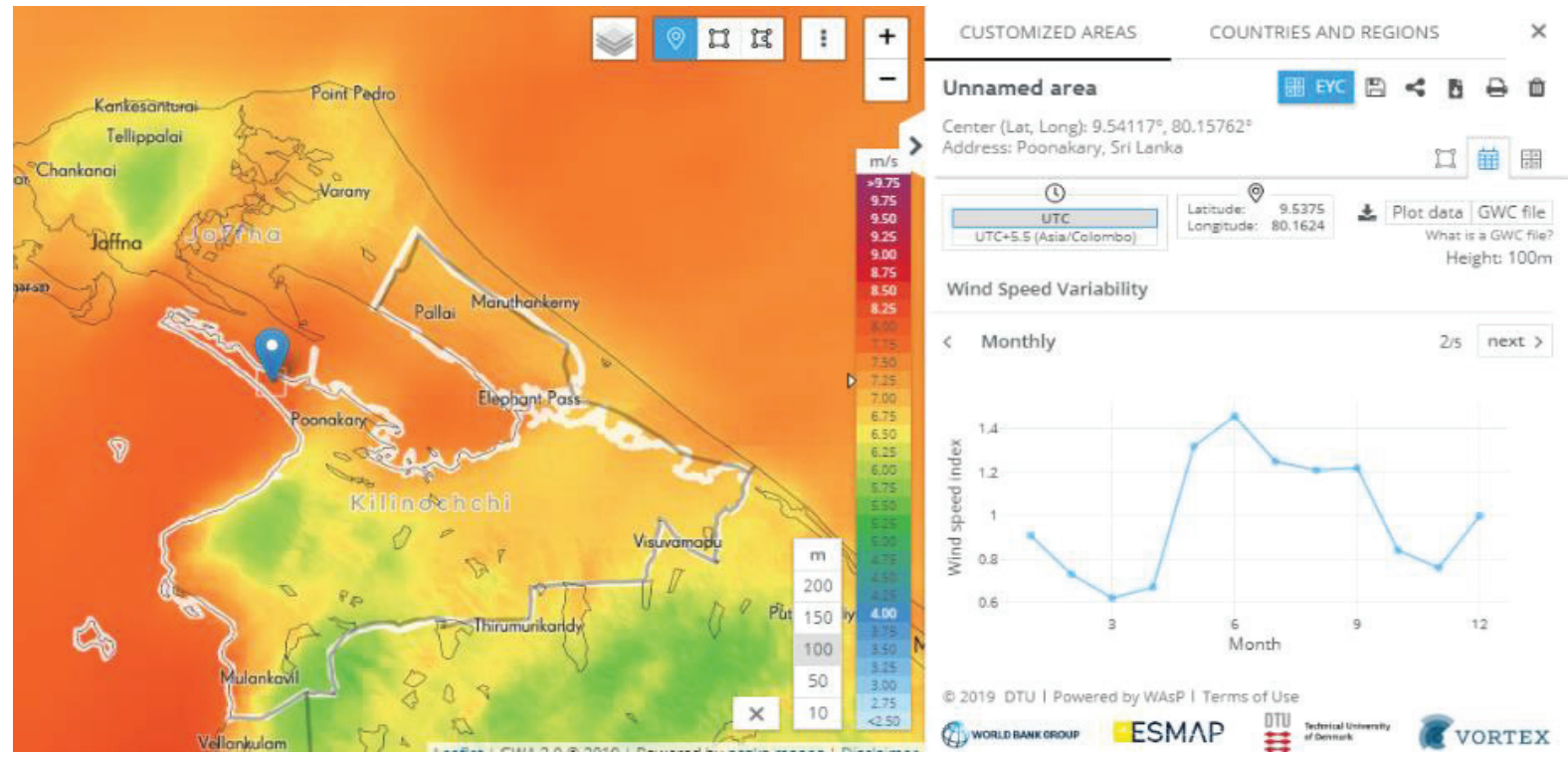

Figure A4 - Wind Speed Index at Kilinochchi

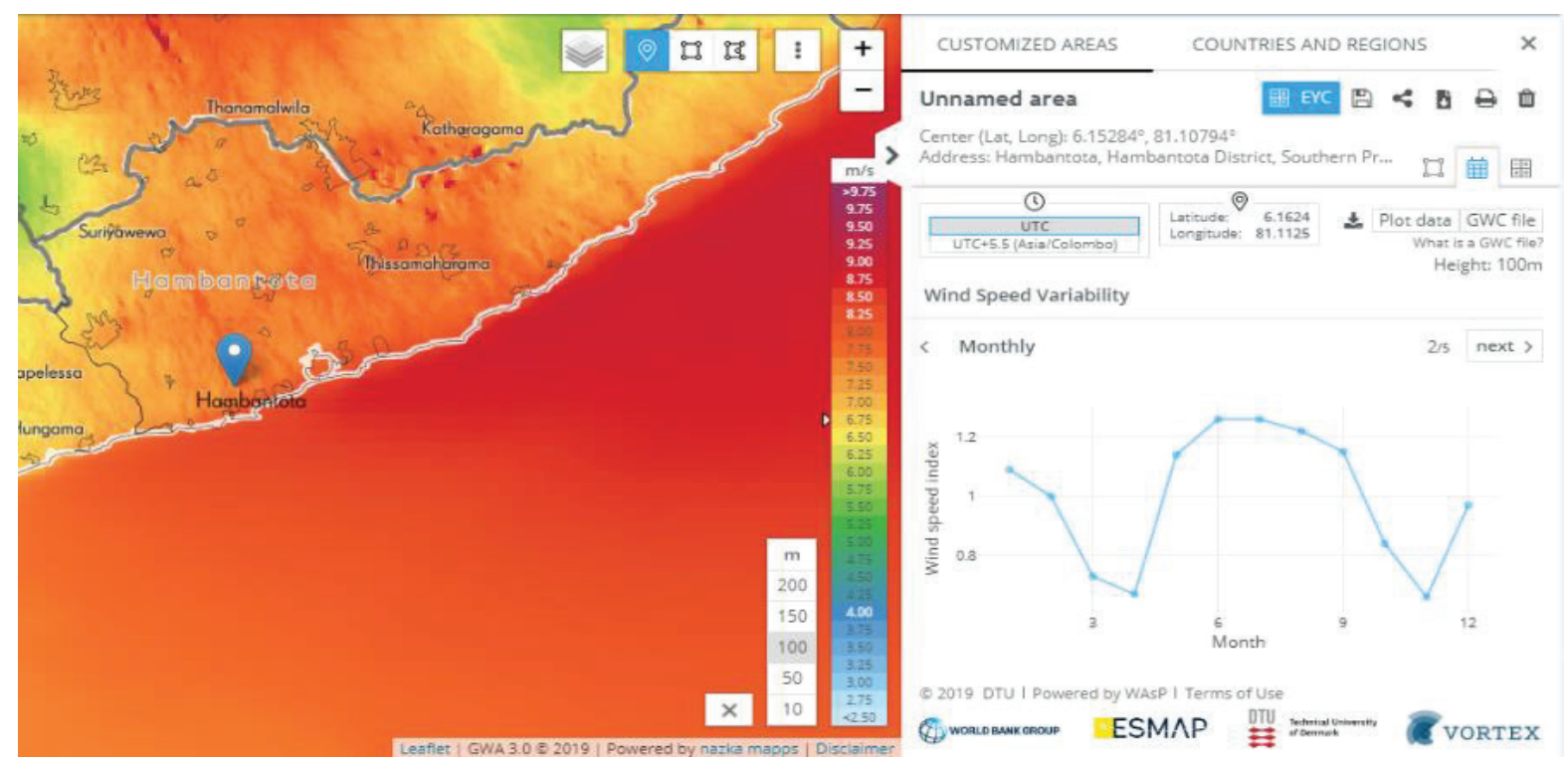

Figure A5 - Wind Speed Index at Hambanota 


\section{Appendix B - Wind Speed Roses at 5 Clusters}

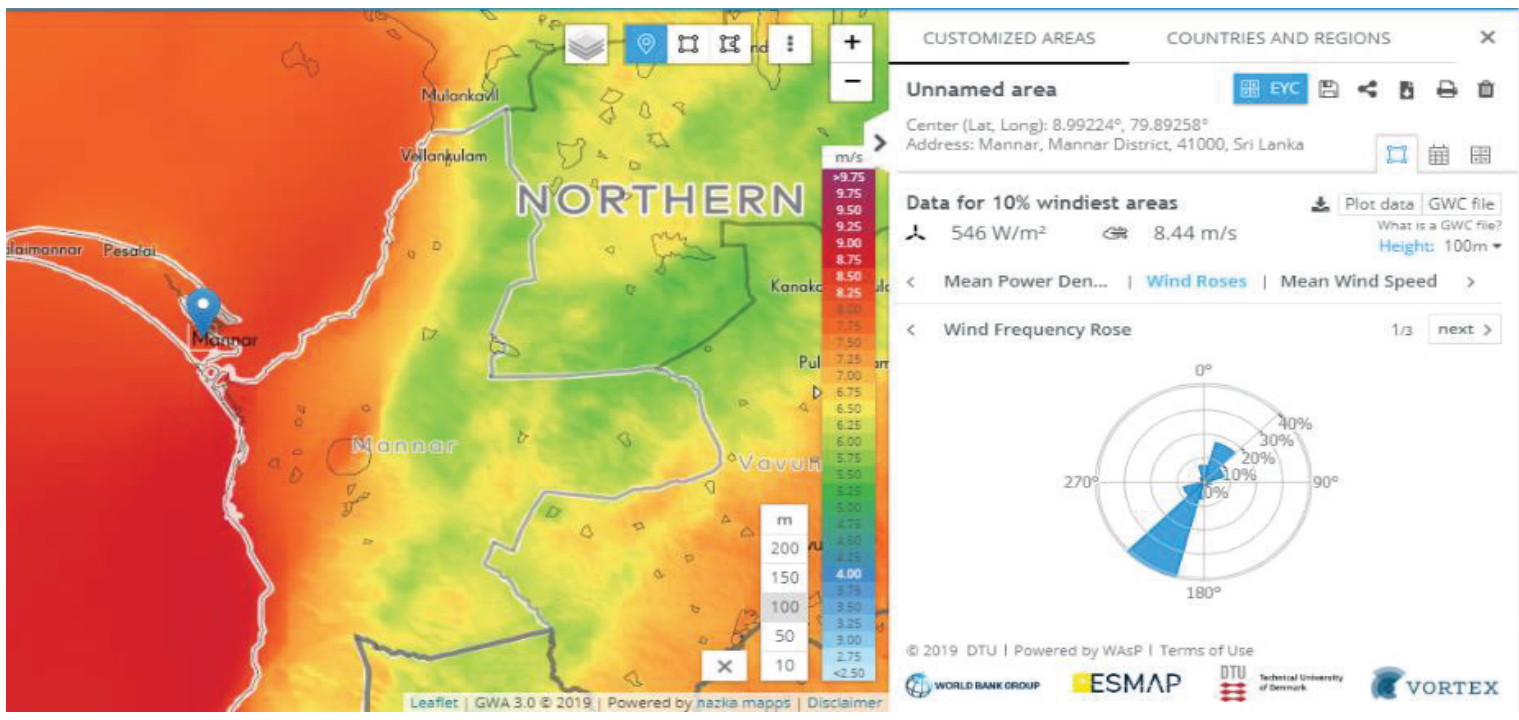

Figure B1 - Wind Rose at Mannar

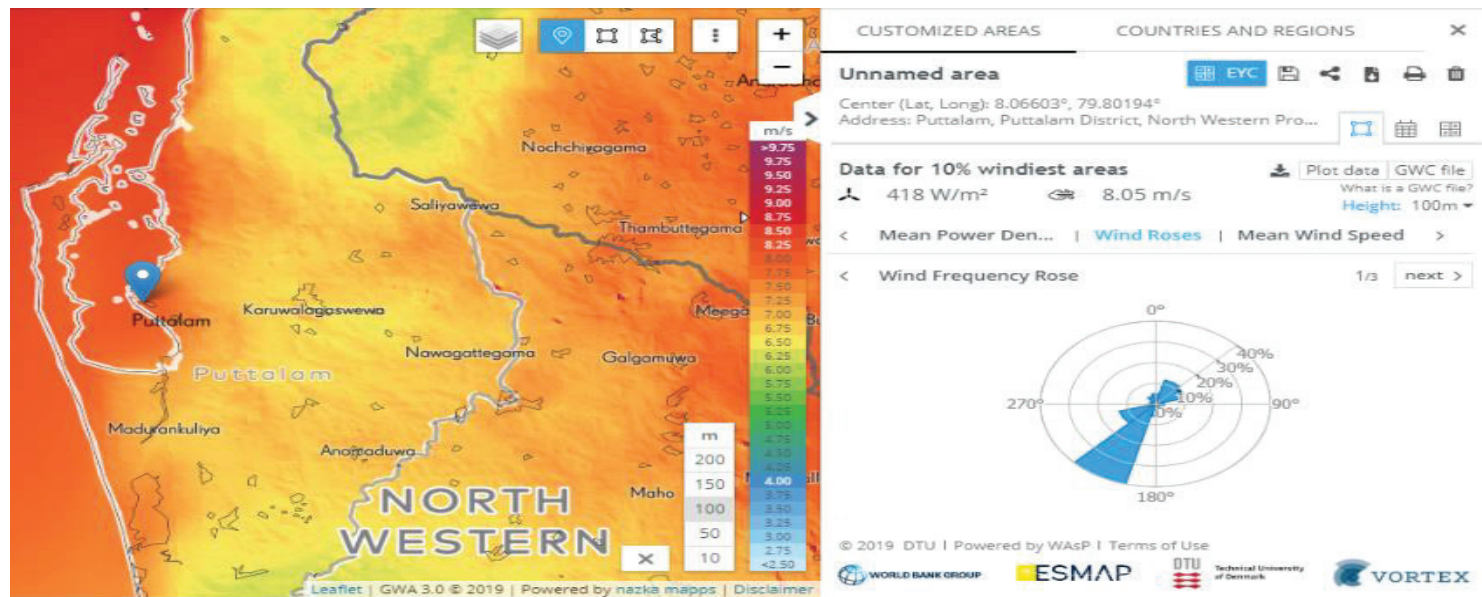

Figure B2 - Wind Rose at Puttalam

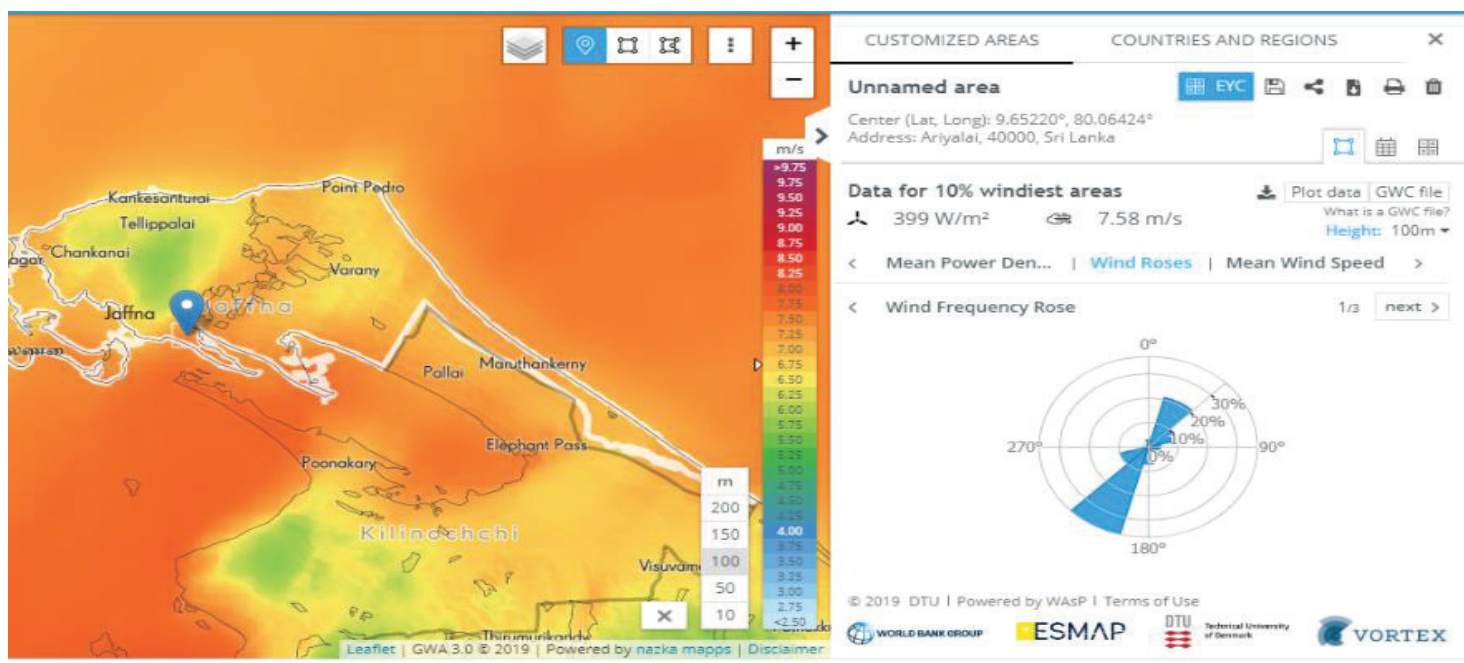

Figure B3 - Wind Rose at Jaffna 


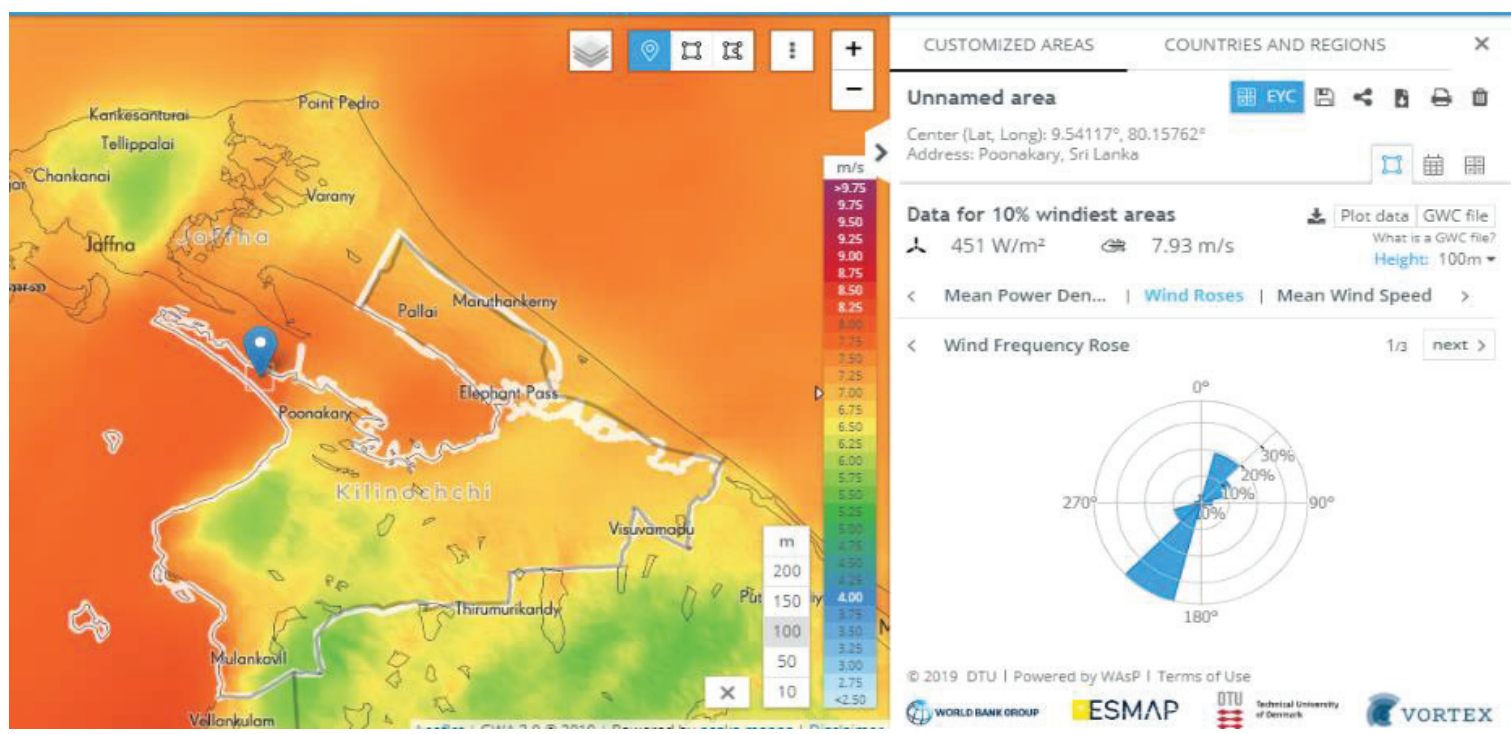

Figure B4 - Wind Rose at Kilinochchi

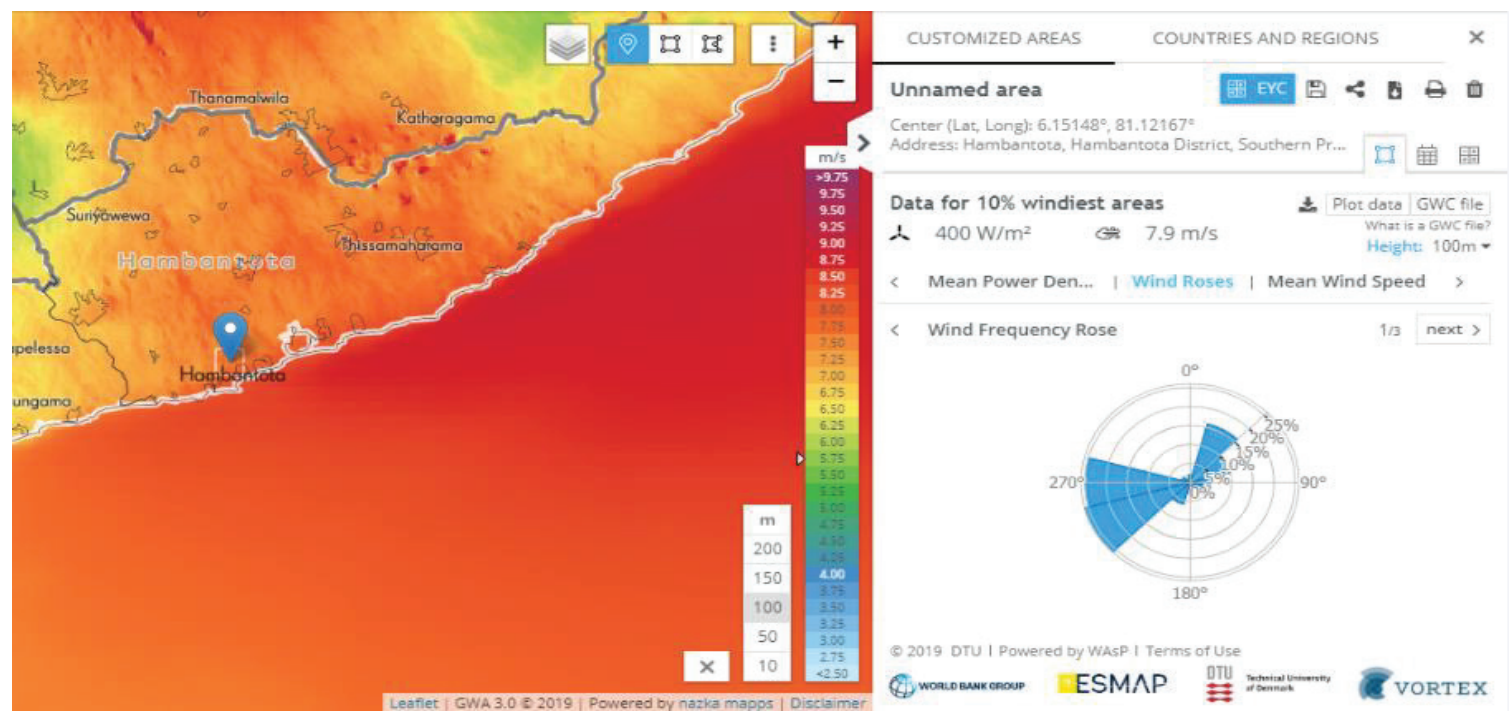

Figure B5 - Wind Rose at Hambantota 